\title{
Mirbelia oxylobioides F. Muell. Leaf Extracts Lack Antibacterial Activity and are Non-toxic in vitro
}

\author{
Ian Edwin $\operatorname{Cock}^{1,2, *}$ \\ 'Environmental Futures Research Institute, Griffith University, 170 Kessels Rd, Nathan, Brisbane, Queensland, AUSTRALIA. \\ ${ }^{2}$ School of Environment and Science, Nathan Campus, Griffith University, 170 Kessels Rd, Nathan, Brisbane, Queensland, AUSTRALIA.
}

\begin{abstract}
Introduction: The development of bacterial strains that are resistant to multiple antibiotics has made the discovery of new antibiotics a priority for medical research. Examination of plants for new antimicrobial agents is an attractive prospect and numerous recent studies have screened plants for antibacterial activity. Despite this, Australian native plants have been relatively neglected. Mirbelia oxylobioides F. Muell. is a native Australian shrub of the family Fabaceae. Very few studies have yet examined species for antibacterial properties against human pathogens. Methods: The ability of $M$. oxyloboides leaf extracts to inhibit the growth of a panel of bacterial pathogens was investigated by disc diffusion assay. Toxicity was examined using the Artemia franciscana nauplii bioassay. Results: $M$. oxyloboides methanolic and aqueous extracts were ineffective at inhibiting the growth of gram-positive and gram-negative panels of bacteria. The extracts were non-toxic or of low toxicity following $24 \mathrm{~h}$ exposure. Conclusion: The M. oxyloboides leaf extracts lacked growth inhibitory bioactivity against
\end{abstract}

a panel of pathogenic bacteria and were non-toxic in the Artemia nauplii assay. However, these extracts may have other therapeutic properties and testing against protozoa, fungi, virus and tumour cells is required.

Key words: Fabaceae, Mountain mirbelia, Sandstone bushpea, Australian plants, Traditional medicine, Medicinal plants, Toxicity.

\section{Correspondence:}

\section{Dr. Ian Edwin Cock}

${ }^{1}$ Environmental Futures Research Institute, Griffith University, 170 Kessels Rd, Nathan, Brisbane, Queensland, AUSTRALIA.

${ }^{2}$ School of Environment and Science, Nathan Campus, Griffith University, 170 Kessels Rd, Nathan, Brisbane, Queensland, AUSTRALIA.

Phone no: +61737357637

E-mail: i.cock@griffith.edu.au

DOI: $10.5530 /$ pc.2021.2.19

\section{INTRODUCTION}

The use of natural plant therapeutics is as old as human civilisation and in many regions of the world is still the primary modality of health care. Ayuverdic medicine in India for example is still commonly practiced, with approximately $85 \%$ of Indians using crude plant preparations for the treatment of various diseases and ailments. ${ }^{1}$ Even in Western civilisations, plants play an important role in medicine. At least $25 \%$ of pharmaceuticals prescribed worldwide are directly obtained from plants and many more drugs are semi-synthetic derivatives of natural plant precursors. ${ }^{2-4}$ Examples of medicinally important plant derived compounds include the anti-malarial drug quinine and its derivatives (from Cinchona spp.), the antitumour drugs vincristine and vinblastine (from Catharanthus roseus) along with the semi-synthetic analogue vindesine, the analgesics morphine and codeine (from Papaver somniferum), the anticholinogenic drug atropine derived from plants of the family Solinaceae (Atropa belladonna, Datura stramonium and Mandragora officinarum), the anticancer drug taxol (derived from Taxus brevifolia) and the cardiac glycoside digoxin (from Digitalis purpurea). ${ }^{5}$

Despite the potential of plants to provide us with useful pharmaceutical agents, the field is still poorly studied. Only an estimated 5-10\% of the approximately 300, 000-500, 000 plant species worldwide have been screened for 1 or more bioactivities. ${ }^{5}$ With so many plant species yet to be tested, it is essential that plant selection processes narrow the field. The main selection criteria currently used is to select plants on the basis of ethnobotanical usage as traditional medicines. Another important selection method is to examine plants closely related to plants for which medicinal potential is well established. Many plant secondary metabolites are regarded as family, genus or species specific and investigation of species closely related to those used as traditional medicines may lead to natural therapeutic discovery. ${ }^{2}$ Plants species may also be selected for study based on their phytochemical contents, and are often also selected randomly. ${ }^{6}$

In recent years, the development of bacterial pathogens that are either extremely (XDR) or totally drug resistant (TDR) to common clinically used antibiotics ${ }^{7}$ has resulted in the need to develop new antibiotic chemotherapies. There are now limited therapeutic options for many diseases caused by bacterial pathogens and the situation is expected to worsen in the future as bacteria exchange resistance genes. Indeed, the development of alternative antibacterial treatment modalities has become crucial and is considered by the World Health Organisation (WHO) to be one of the most serious challenges facing medical science ${ }^{8}$ For a number of reasons reviewed elsewhere, ${ }^{7}$ it is unlikely that the previous methods of antibiotic discovery/development will be as successful in the future and new treatment modalities are urgently required. Traditional medicines and herbal remedies have great potential for antimicrobial drug development and there has recently been a substantial increase in interest in this field. ${ }^{9-20}$

Mirbelia oxylobioides F.Muell. (commonly known as sandstone bushpea, mountain Mirbelia; Figure 1) is an erect shrub to $1.5 \mathrm{~m}$ high that grows in dry sclerophyll forests (particularly at high altitudes) on the east coastal regions of southeastern and eastern Australia. It has ovate to elliptical leaves $2-10 \mathrm{~mm}$ long by $1-4 \mathrm{~mm}$ wide that are generally opposite or whorled on the stems. M. oxyloboidies produces small orange/ yellow flowers (up to $10 \mathrm{~mm}$ ) with red markings between October and January. We were unable to find records of usage by the first Australians for medicinal purposes. Similarly, few studies have screened this plant species for therapeutic properties, although some recent studies have screened this species against limited panels of bacteria. ${ }^{21}$ Similarly, there is a lack of information on the phytochemical composition of this species. This study was undertaken to screen M. oxylobioides leaf extracts for the ability to inhibit the growth of a panel of gram-positive and gramnegative bacterial pathogens of importance to human health. 


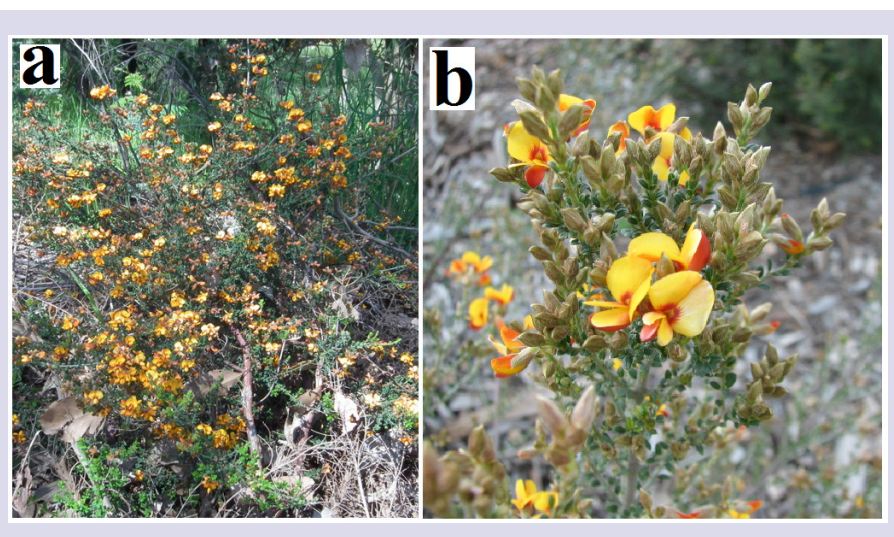

Figure 1: M. oxylobioides (a) whole shrub, (b) leaves and flowers.

\section{MATERIALS AND METHODS}

\section{Collection of Plant Material and Extraction}

Mirbelia oxylobioides F.Muell. leaves were obtained from and identified by Philip Cameron, senior botanic officer, Mt Cootha Botanical Gardens, Brisbane, Australia. The leaves were washed in deionised water and dried in a Sunbeam food dehydrator dried within $4 \mathrm{hr}$ of collection. The dried leaves were subsequently was ground to a coarse powder using a coffee grinder. Individual $1 \mathrm{~g}$ masses of the dried plant material was extracted extensively in 50mL methanol (Ajax, AR grade) or deionised water for $24 \mathrm{~h}$ at $4^{\circ} \mathrm{C}$ with gentle shaking. The extract was filtered through filter paper (Whatman No. 54) under vacuum followed by drying by rotary evaporation. The resultant pellet was dissolved in $5 \mathrm{~mL}$ deionised water (containing 1\% DMSO) and passed through $0.22 \mu \mathrm{m}$ filter (Sarstedt) and stored at $4^{\circ} \mathrm{C}$.

\section{Qualitative Phytochemical Studies}

Phytochemical analysis of the $M$. oxyloboides leaf extracts for the presence of saponins, phenolic compounds, flavonoids, phytosteroids, triterpenoids, cardiac glycosides, anthraquinones, tannins and alkaloids was conducted using standard assays. ${ }^{22-24}$

\section{Antibacterial Screening}

\section{Test Microorganisms}

All media was purchased from Oxoid Ltd., Australia. The reference strains of E. coli (ATCC157293), Klebsiella pneumoniae (ATCC31488), Proteus mirabilis (ATCC21721) and Streptococcus pyogenes (ATCC19615) were purchased from American Tissue Culture Collection (ATCC), USA. Clinical isolate microbial strains of Aeromonas hydrophilia, Alcaligenes feacalis, Bacillus cereus, Citrobacter freundii, Pseudomonas fluorescens, Salmonella newport, Serratia marcescens, Shigella sonneii, Staphylococcus aureus and Staphylococcus epidermidis strains were obtained from Ms Michelle Mendell and Ms Jane Gifkins, Griffith University. All stock cultures were subcultured and maintained in nutrient broth at $4^{\circ} \mathrm{C}$.

\section{Evaluation of Antimicrobial Activity}

Antimicrobial activity of the M. oxyloboides leaf extracts was determined using a modified disc diffusion assay. ${ }^{25-28}$ Briefly, $100 \mu \mathrm{L}$ of the each bacterial suspension in log phase was spread onto individual nutrient agar plates and the extracts were tested for antibacterial activity using $6 \mathrm{~mm}$ sterilised filter paper discs. The discs were each infused with $10 \mu \mathrm{L}$ of the individual plant extract, allowed to dry and placed onto the inoculated plates. The plates were allowed to stand at $4^{\circ} \mathrm{C}$ for $2 \mathrm{~h}$ before incubation at $37^{\circ} \mathrm{C}$ for $24 \mathrm{~h}$. The diameters of the zones of inhibition (ZOIs) were measured to the closest whole millimetre. Each assay was performed three times in triplicate $(n=9)$. Mean values $( \pm$ SEM) are reported in this study. Standard discs of ampicillin $(10 \mu \mathrm{g})$ and chloramphenicol $(10 \mu \mathrm{g})$ were obtained from Oxoid, Australia and were used as positive controls to compare antibacterial activity. Filter discs infused with $10 \mu \mathrm{L}$ of distilled water were used as a negative control.

\section{Artemia franciscana Nauplii Toxicity Screening}

Toxicity was tested using an adapted Artemia franciscana nauplii lethality assay. ${ }^{29-31}$ Briefly, A. franciscana nauplii were incubated in the presence of the extracts, reference toxin $(1 \mathrm{mg} / \mathrm{mL}$ potassium dichromate) or artificial seawater (negative control) at $25 \pm 1^{\circ} \mathrm{C}$ under artificial light. All treatments were performed three times, each with internal triplicates $(n=9)$. The number of dead were counted in each well at $24 \mathrm{~h}, 48 \mathrm{~h}$ and $72 \mathrm{~h}$. At the completion of the $72 \mathrm{~h}$ exposure period, the remaining live nauplii were sacrificed and the total number of nauplii in each well were counted and used to calculate the $\%$ mortality per well. LC $_{50}$ values were calculated for each treatment using probit analysis.

\section{Statistical analysis}

Data are expressed as the mean \pm SEM of three independent experiments with internal triplicates $(n=9)$. One way ANOVA was used to calculate statistical significance between control and treated groups, with a $P$ value $<0.01$ considered to be statistically significant.

\section{RESULTS}

\section{Liquid extraction yields and qualitative phytochemical screening}

Extraction of $1 \mathrm{~g}$ of dried and powdered M. oxyloboides leaves with methanol and water yielded 314 and $306 \mathrm{mg}$ of extracted material respectively (Table 1 ). The extracts were resuspended in $10 \mathrm{~mL}$ of deionised water (containing 1\% DMSO), resulting in an extract concentrations shown in Table 1. Qualitative phytochemical screening studies showed that both extracts had similar phytochemical profiles. Both contained high levels of phenolic compounds and flavonoids. Moderate levels of saponins and tannins were also detected in each extract. Lower levels of triterpenoids were also detected. Cardiac glycosides, phytosterols, alkaloids and anthraquinones were completely absent or below the detection thresholds for these assays.

\section{Antibacterial activity}

To determine the growth inhibitory activity of the $M$. oxyloboides leaf extracts, aliquots $(10 \mu \mathrm{L})$ of each extract were screened in the disc diffusion assay. The $M$. oxyloboides leaf extracts were ineffective at inhibiting the growth of all gram-negative (Figure 2) and gram-positive (Figure 3) bacterial species tested. In contrast, both positive control antibiotics (ampicillin and chloramphenicol) were effective growth inhibitors, with ZOI's of up to $14.3 \mathrm{~mm}$ (chloramphenicol against $E$. coli). We were therefore unable to determine the MIC values for any extract.

\section{Quantification of Toxicity}

The toxicity of the M. oxyloboides leaf extracts was initially tested at $2 \mathrm{mg} /$ $\mathrm{mL}$ in the A. franciscana nauplii bioassay (Figure 4). The mortality in the presence of both extracts was not significantly different to that of the untreated control at $24 \mathrm{~h}$ and thus both extracts were deemed to be nontoxic. Extracts with $24 \mathrm{~h} \mathrm{LC}_{50}$ values $>1000 \mu \mathrm{g} / \mathrm{mL}$ have previously been defined as non-toxic. ${ }^{29}$ In contrast, the potassium dichromate positive control induced substantial mortality within $4 \mathrm{~h}$ (results not shown), with $100 \%$ mortality induction seen by $24 \mathrm{~h}$. The mortality increased 


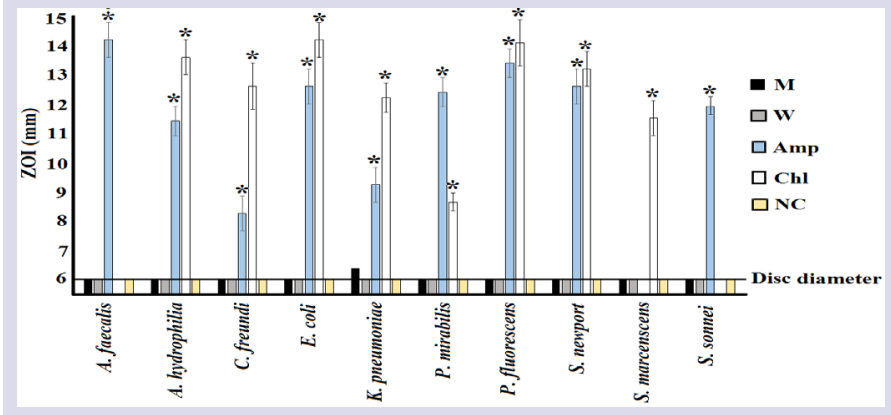

Figure 2: Growth inhibitory activity of $M$. oxyloboides leaf extracts and reference antibiotics against gram-negative bacterial species measured as ZOls $(\mathrm{mm}) \pm \mathrm{SEM}$. Ampicillin (Amp) and chloramphenicol (Chl) standard discs $(10 \mu \mathrm{g})$ were used as positive controls. $\mathrm{M}=$ methanolic extract; $\mathrm{W}=$ aqueous extract; NC = negative control. All assays were completed three times, each with internal triplicates $(n=9)$ and the results are expressed as mean zones of inhibition $(\mathrm{mm}) \pm \mathrm{SEM}$.

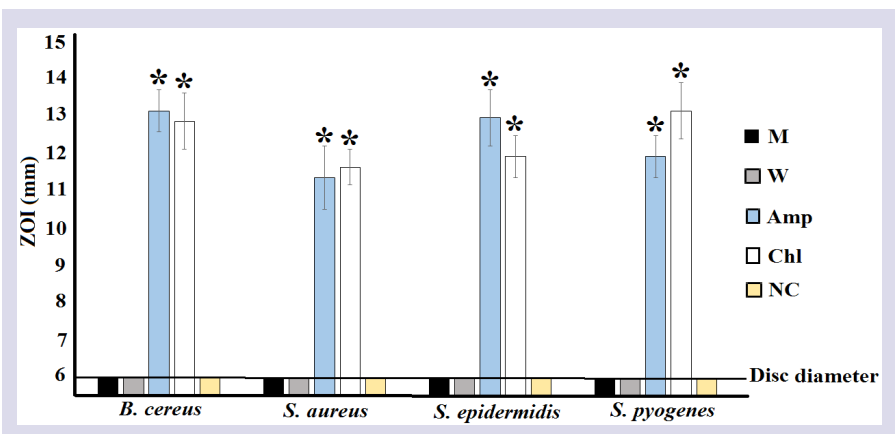

Figure 3: Growth inhibitory activity of $M$. oxyloboides leaf extracts and reference antibiotics against gram-positive bacterial species measured as ZOls $(\mathrm{mm}) \pm \mathrm{SEM}$. Ampicillin (Amp) and chloramphenicol (Chl) standard discs $(10 \mu \mathrm{g})$ were used as positive controls. $\mathrm{M}=$ methanolic extract; $\mathrm{W}=$ aqueous extract; NC = negative control. All assays were completed three times, each with internal triplicates $(n=9)$ and the results are expressed as mean zones of inhibition $(\mathrm{mm}) \pm$ SEM.

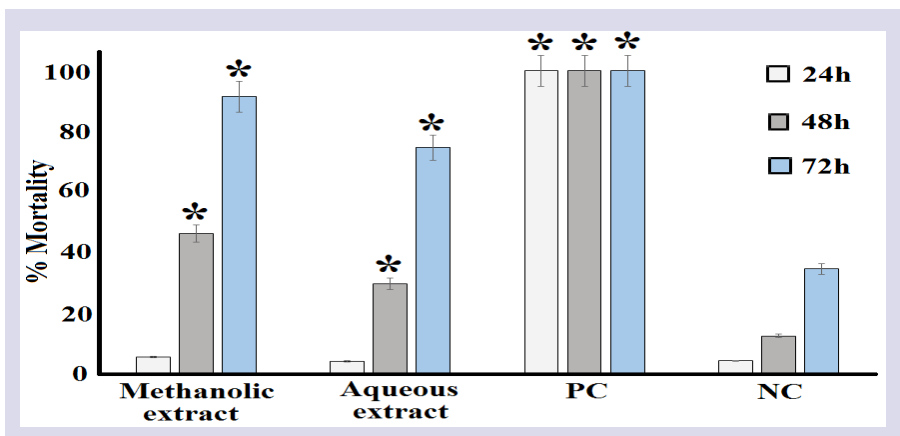

Figure 4: The lethality of the $M$. oxyloboides leaf extracts, potassium dichromate control $(1000 \mu \mathrm{g} / \mathrm{mL}$ ) and seawater (negative control) following 24,48 and $72 \mathrm{hr}$ of exposure. All bioassays were performed three times in triplicate $(n=9)$ and are expressed as mean \pm SEM. ${ }^{*}$ indicates results that are significantly different to the untreated (seawater) control at the equivalent exposure time $(P<0.01)$.
Table 1: The mass of dried extracted material, the concentration after resuspension in deionised water and qualitative phytochemical screenings of the M. oxyloboides leaf extracts.

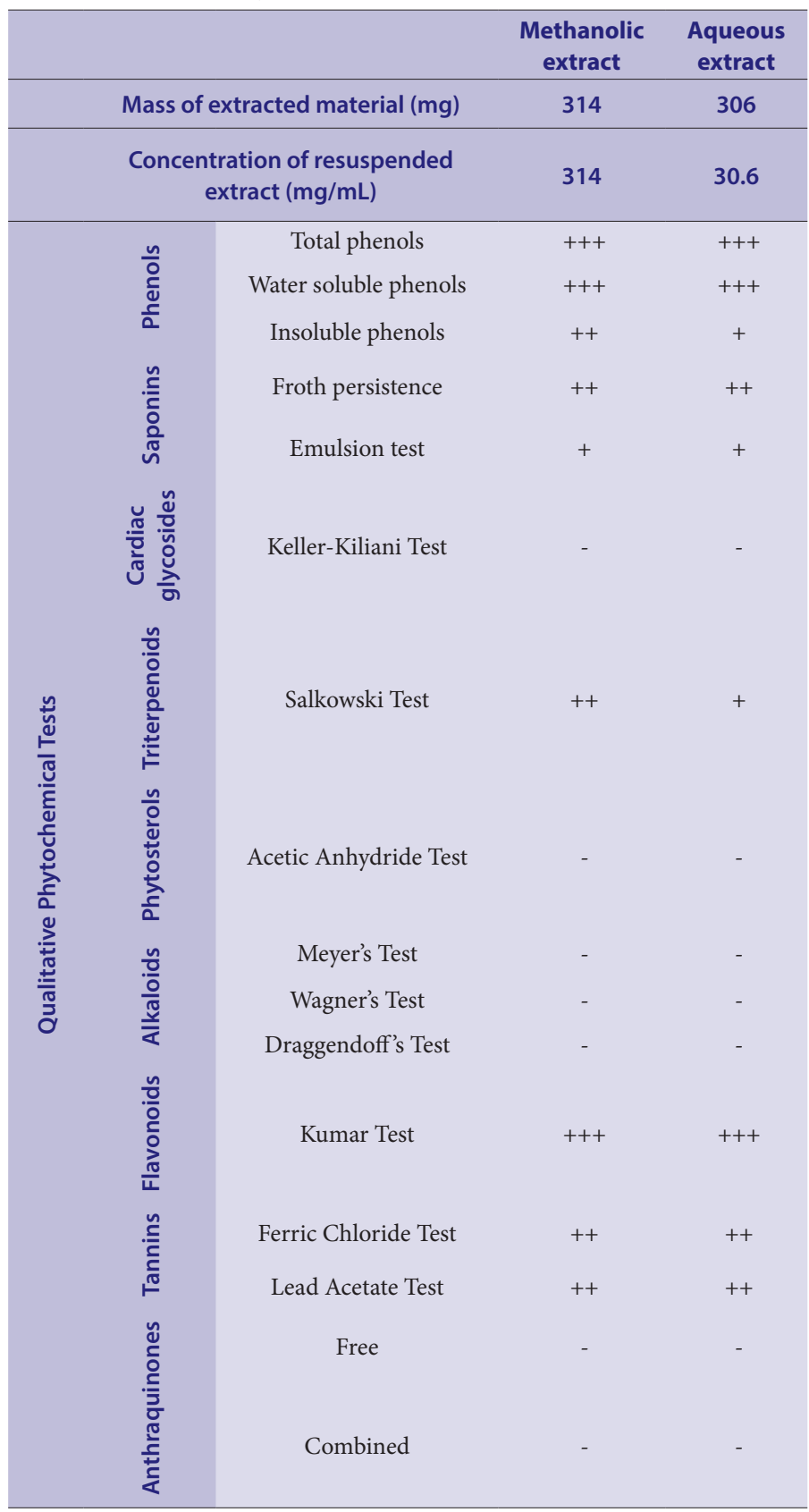

+++ indicates a large response; ++ indicates a moderate response; + indicates a minor response; - indicates no response in the assay.

following exposure to the M. oxyloboides leaf extracts at $48 \mathrm{~h}$ and was further increased following $72 \mathrm{~h}$ exposure.

\section{DISCUSSION}

Due to recent increases in bacterial resistance to many antibiotics, the development of new antibiotic chemotherapies is a high priority for medical science. ${ }^{7,8} \mathrm{~A}$ concurrent decrease in the discovery of new antibiotic medicines by conventional strategies has increased interest in evaluating plants for new antibiotic chemotherapies. ${ }^{32}$ As M. oxyloboides has not been rigorously tested for any therapeutic activity, it was 
deemed a viable target for antibacterial screening. Interestingly, the $M$. oxyloboides methanolic and aqueous extracts were completely inactive against all gram-positive and gram-negative bacteria tested. However, it is noteworthy that a single assay technique was used to screen for antibacterial activity in this study. We chose to use the disc diffusion assay as it is rapid and it has previously been widely utilised in other studies. Therefore, comparisons between studies are relatively simple.

As the disc diffusion method is reliant on the diffusion of a molecule through the aqueous environment of an agar gel, this assay may be affected by the solubility of the extract compounds in the aqueous environment. Polar compounds that are highly soluble in water would be expected to diffuse easily in the gel, whereas less soluble compounds would not diffuse as readily and thus will be concentrated around the disc. For this reason, whilst this is a handy assay for screening aqueous extracts, this technique may not be ideal for nonpolar compounds (e.g. when screening essential oils and their components). For examining nonpolar mixtures, other techniques such as liquid dilution assays are preferred. Interestingly, the phytochemical screening studies presented herein reports the presence of saponins (which are relatively nonpolar) within the mentaholic and aqueous extracts. It is therefore possible that these compounds may not contribute significantly to the potential antibacterial activity of these extracts as they remain at or near the discs and are unable to diffuse through the solid agar media. Thus, the growth inhibitory activity of the $M$. oxyloboides extracts may have been significantly under estimated using this assay. Liquid dilution studies may have been better suited to screen the M. oxyloboides extracts for activity and future studies will use these techniques to re-examine the extracts for antibacterial activity.

Diffusion of molecules within an agar gel is also affected by the size of the molecules. The movement of large, complex phytochemicals (e.g. complex tannins) through agar gels by diffusion would also be retarded and may provide a false idea of the efficacy of an extract. As many tannins have well described antibiotic properties, screening for growth inhibition using agar diffusion techniques may give a distorted view of its inhibitory potential.

The findings reported here also indicate that the extracts examined were non-toxic $\left(24 \mathrm{hr} \mathrm{LC}_{50}>1000 \mu \mathrm{g} / \mathrm{mL}\right)$ in the Artemia nauplii bioassay. Whilst toxicity was assessed in this study with the test organism $A$. franciscana, toxicity towards A. franciscana has previously been shown to correlate well with toxicity towards human cells for many toxins. ${ }^{29}$ However, further studies are required to determine whether this is also true for the M. oxyloboides leaf extracts examined in these studies.

\section{CONCLUSION}

Methanolic and aqueous M. oxyloboides leaf extracts displayed low or no antibacterial activity in the disc diffusion assay against a panel of human pathogenic bacteria. The extracts were non-toxic towards Artemia nauplii.

\section{ACKNOWLEDGEMENT}

The authors are grateful to Michelle Mendell and Jane Gifkins of Griffith University for providing the clinical bacterial strains used in this study. Financial support for this work was provided by the Environmental Futures Research Institute and the School of Natural Sciences, Griffith University, Australia.

\section{CONFLICT OF INTEREST}

The authors report no conflicts of interest.

\section{ABBREVIATIONS}

DMSO: Dimethyl sulfoxide; $\mathbf{L C}_{50}$ : The concentration required to achieve $50 \%$ mortality; MIC: minimum inhibitory concentration; ZOI: zone of inhibition.

\section{REFERENCES}

1. Kamboj VP. Herbal medicine. Curr Sci. 2000;78(1):35-9

2. Hostettmann K, Hamburger M. Search for new lead compounds of natural origin. In Perspectives in Medical Chemistry. Verlag Helvitica Acta, Basel. 1993.

3. Newman DJ, Cragg GM, Snader KM. The influence of natural products on drug discovery. Nat Prod Rep. 2000;17(3):215-34

4. Walsh G. Biopharmaceuticals: Biochemistry and Biotechnology. $3^{\text {rd }}$ ed. Wiley, Chinchester. 2003.

5. Gilani AH. Trends in ethnopharmacology. J Ethnopharmacol. 2005;100(1-2):439.

6. Cock IE. Medicinal and aromatic plants - Australia, in Ethnopharmacology section, Biological, Physiological and Health Sciences, Encyclopedia of Life Support Systems (EOLSS), Developed under the Auspices of the UNESCO, EOLSS Publishers, Oxford, UK. 2011. (http://www.eolss.net).

7. Cheesman MJ, Ilanko A, Blonk B, Cock IE. Developing new antimicrobial therapies: Are synergistic combinations of plant extracts/compounds with conventional antibiotics the solution?. Pharmacognosy Reviews. 2017;11(22):57-72. DOI: 10.4103/phrev.phrev_21_17

8. WHO. Antimicrobial Resistance. World Health Organization. 2016. Available from: http://www.who.int/mediacentre/factsheets/fs194/en/. [Cited on 2020 September 10].

9. Sirdaarta J, Matthews B, Cock IE. Kakadu plum fruit extracts inhibit the growth of the bacterial triggers of rheumatoid arthritis: Identification of stilbene and tannin components. J Funct Food. 2015;17:610-20. DOI: 10.1016/j.jff.2015.06.019

10. Ilanko $A$, Cock IE. The interactive antimicrobial activity of contentional antibiotics and Petalostigma spp. extracts against bacterial triggers of some autoimmune inflammatory diseases. Pharmacogn J. 2019;11(2):292-309. DOI: 10.5530/pj.2019.11.45

11. Winnett V, Sirdaarta J, White A, et al. Inhibition of Klebsiella pneumonia growth by selected Australian plants: Natural approaches for the prevention and management of ankylosing spondylitis. Inflammopharmacol. 2017;25(2):223-35. DOI: 10.1007/s10787-017-0328-1

12. Cheesman M, White A, Matthews $B$, et al. Terminalia ferdinandiana fruit and leaf extracts inhibit methicillin-resistant Staphylococcus aureus growth. Planta Medica . 2019;85(16):1253-62. DOI: 10.1055/a-1013-0434

13. Cock IE, Van Vuuren SF. The traditional use of southern African medicinal plants for the treatment of bacterial respiratory diseases: A review of the ethnobotany and scientific evaluations. J Ethnopharmacol 2020;113204. DOI: 10.1016/j. jep.2020.

14. Courtney R, Sirdaarta J, Matthews B, et al. Tannin components and inhibitory activity of Kakadu plum leaf extracts against microbial triggers of autoimmune inflammatory diseases. Pharmacogn J. 2015;7(1):18-31. DOI: 10.5530/ pj.2015.7.2

15. Hübsch Z, Zyl RLV, Cock IE, et al. Interactive antimicrobial and toxicity profiles of convential antimicrobials with Southern African medicinal plants. S Afr J Bot 2014;93:185-97. DOI: 10.1016/j.sajb.2014.04.005

16. Tiwana G, Cock IE, White A, et al. Use of specific combinations of the triphala plant component extracts to potentiate the inhibition of gastrointestinal bacterial growth. J Ethnopharmacol. 2020;260:112937. DOI: 10.1016/j.jep.2020.112937

17. Mandeville A, Cock IE. Terminalia chebula Retz. fruit extracts inhibit bacterial triggers of some autoimmune diseases and potentiate the activity of tetracycline. Indian J Microbiol. 2018;58(4):496-506. DOI: 10.1007/s12088-018-0754-9

18. Omer E, Elshamy Al, Nassar M, et al. Plantago squarrosa Murray extracts inhibit the growth of some bacterial triggers of autoimmune diseases: GC-MS analysis of an inhibitory extract. Inflammopharmacol. 2019;27(2):373-85. DOI: 10.1007/s10787-018-0547-0

19. Ilanko P, McDonnell PA, Vuuren SFV, et al. Interactive antibacterial profile of $M o-$ ringa oleifera Lam. Extracts and conventional antibiotics against bacterial triggers of some autoimmune inflammatory diseases. S Afr J Bot. 2019;124:420 35 .

20. Lee CJ, Wright MH, Arnold MSJ, et al. Inhibition of Streptococcus pyogenes growth by native Australian plants: New approaches towards the management of impetigo, pharyngitis and rheumatic heart disease. Pharmacogn Commun 2016;6(3):164-73. DOI: 10.5530/pc.2016.3.6

21. Cock IE. Antibacterial activity of selected Australian native plant extracts. Internet J. Microbiol. 2008;4(2):1-8

22. Wright $\mathrm{MH}$, Matthews $\mathrm{B}$, Arnold MSJ, et al. The prevention of fish spoilage by high antioxidant Australian culinary plants: Shewanella putrefaciens growth inhibition. Internat J Food Sci Technol. 2016;51(3):801-13. DOI: 10.1111/ijfs.13026

23. Rayan P, Matthews B, McDonnell PA, et al. Terminalia ferdinandiana extracts as inhibitors of Giardia duodenalis proliferation: A new treatment for giardiasis. 
Parasitol Res. 2015;114(7):2611-20. DOI: 10.1007/s00436-015-4465-4

24. Noé W, Murhekar S, White A, et al. Inhibition of the growth of human dermatophytic pathogens by selected Australian and Asian plants traditionally used to treat fungal infections. Journal de Mycologie Médicale. 2019;29(4):331-44. DOI: 10.1016/j.mycmed.2019.05.003

25. Wright MH, Sirdaarta J, White A, et al. GC-MS headspace analysis of Terminalia ferdinandiana fruit and leaf extracts which inhibit Bacillus anthracis growth. Pharmacogn J. 2017;9(1):73-82. DOI: 10.5530/pj.2017.1.14

26. McManus K, Wood A, Wright MH, et al. Terminalia ferdinandiana Exell. extracts inhibit the growth of body odour-forming bacteria. Internat J Cosmetic Sci. 2017;39(5):500-10. DOI: 10.1111/ics.12403

27. Hutchings A, Cock IE. An interactive antimicrobial activity of Embelica officinalis Gaertn. Fruit extracts and conventional antibiotics against some bacterial triggers of autoimmune inflammatory diseases. Pharmacogn J. 2018;10(4):654-62. DOI: $10.5530 /$ pj.2018.4.108
28. Rabadeaux C, Vallette L, Sirdaarta J, et al. An examination of the antimicrobial and anticancer properties of Khaya senegalensis (Desr.) A. Juss. bark extracts. Pharmacogn J. 2017:9(4):504-18. DOI: 10.5530/pj.2017.4.82

29. Cock IE, Ruebhart DR. Comparison of the brine shrimp nauplii bioassay and the Tox Screen-II test for the detection of toxicity associated with Aloe vera (Aloe barbadensis Miller) leaf extract. Pharmacognosy Research. 2009;1(2):98-101.

30. Shalom J, Cock IE. Terminalia ferdinandiana Exell. fruit and leaf extracts inhibit proliferation and induce apoptosis in selected human cancer cell lines. Nutrit Cancer. 2018;70(4):579-93. DOI: 10.1080/01635581.2018.1460680

31. Wright $\mathrm{MH}$, Shalom J, Matthews $\mathrm{B}$, et al. Terminalia ferdinandiana Exell. ex tracts inhibit Shewanella spp. growth and prevent fish spoilage. Food Microbiology. 2019;78:114-22. DOI: 10.1016/j.fm.2018.10.006

32. Aiyegoro OA, Okoh Al. Use of bioactive plant products in combination with standard antibiotics: Implications in antimicrobial chemotherapy. Journal of Medicinal Plants Research. 2009;3(13):1147-52.

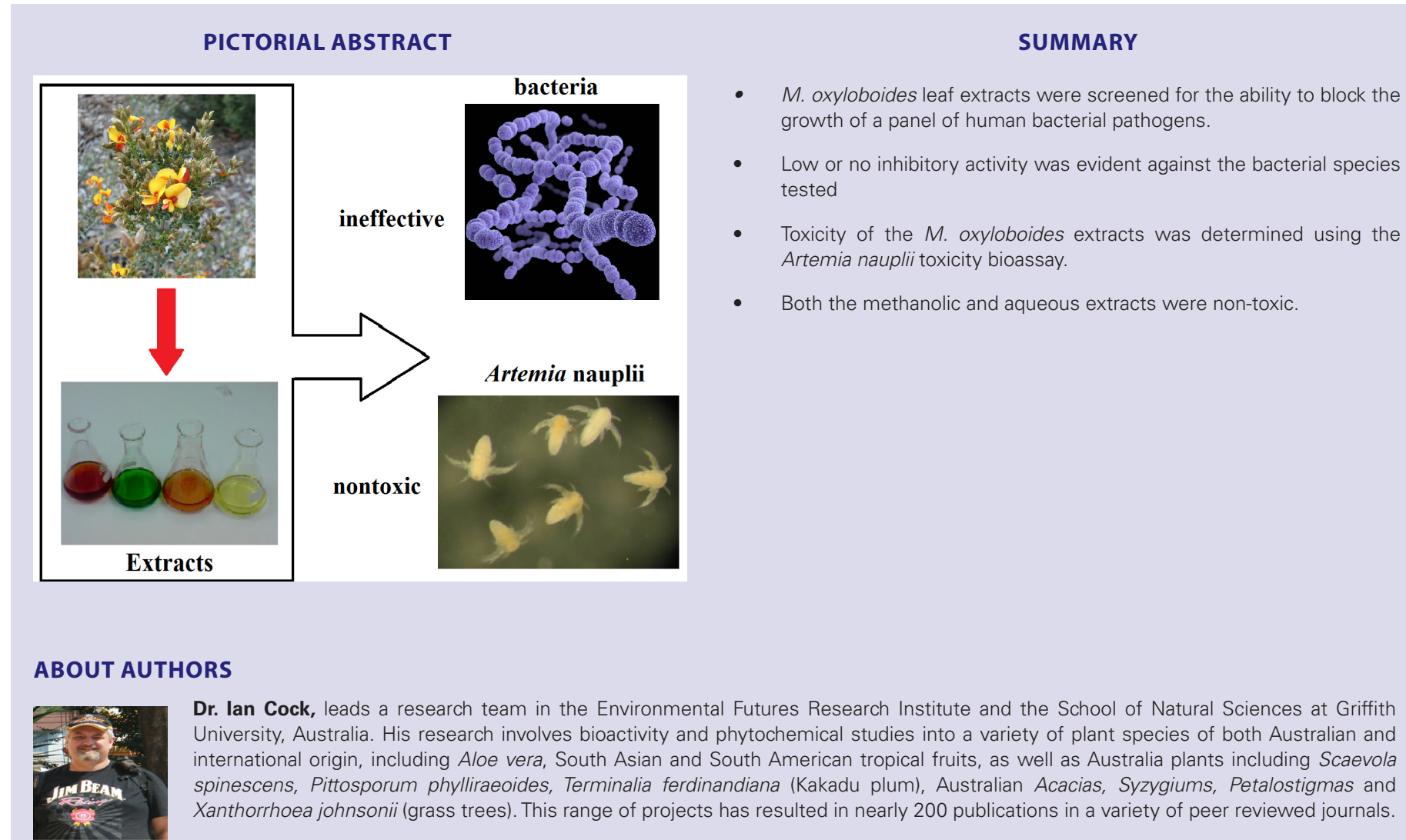

